\title{
The role of inflammation in diabetic cardiomyopathy
}

This article was published in the following Dove Press journal: International Journal of Interferon, Cytokine and Mediator Research 20 July 2012 Number of times this article has been viewed

\section{Sara Nunes \\ Edna Soares \\ Frederico Pereira \\ Flávio Reis}

Laboratory of Pharmacology and Experimental Therapeutics, IBILI, Faculty of Medicine, Coimbra University, Coimbra, Portugal
Correspondence: Flávio Reis Laboratory of Pharmacology and Experimental Therapeutics, IBILI, Medicine Faculty, Sub-Unit I (Pólo III), Coimbra University, 3000-548 Coimbra, Portugal

$\mathrm{Tel}+35$ I 239480053

Fax +35I 239480065

Email freis@fmed.uc.pt
Abstract: Type 2 diabetes mellitus (T2DM) is a major risk factor for developing cardiovascular disease and represents a serious public health problem, with high rates of mortality and morbidity worldwide. T2DM etiology is complex and multifactorial and is associated with several complications, including those at myocardium level. Diabetic cardiomyopathy (DCM) is viewed as a specific cardiomyopathy and defined as structural and functional changes in the myocardium due to metabolic and cellular abnormalities induced by diabetes. T2DM has long been classified as an inflammatory disease and recent studies have identified the importance of the inflammatory process in the development and progression of heart failure. In this review, the authors outline the main mechanisms underlying the potential contribution of the inflammatory process in the development and evolution of DCM. In addition, potential therapeutic strategies against inflammation of DCM are discussed.

Keywords: type 2 diabetes mellitus, inflammation, myocardium, inflammatory process

\section{Introduction}

Type 2 diabetes mellitus (T2DM) is the most common form of diabetes, affecting $90 \%-95 \%$ of the diabetic population. In recent years, the global prevalence of T2DM has increased, so that it has achieved epidemic proportions. Currently, there are over 285 million cases of diabetes and it is estimated that cases will increase to 439 million in $2030 .{ }^{1}$ This progression is even more alarming when considering that over the past 20 years its prevalence has increased dramatically among children and adolescents. $^{2}$

The prevalence of diabetes mellitus (DM) is higher among men, percentage wise; however, there are more women with diabetes worldwide. The most important demographic change to this increased prevalence of DM is an increase in the world's aging population, which translates into an increase in the population of those aged over 65 years. ${ }^{3}$ Although the prevalence of DM is increasing overall, the prevalence of T2DM is increasing more than type $1 \mathrm{DM}$ (T1DM), due to decreased physical activity and increasing population levels of obesity, mainly in developed countries, but also in developing countries that are becoming increasingly industrialized. ${ }^{4}$

In addition to the high prevalence rates, chronic complications of diabetes mean that the disease has a strong impact on health budgets related to disease treatment and hospitalization, as well as with early disability, inability to work, and decreased quality of life; thus, it is becoming a serious public health problem. As it is an ongoing silent disease, which is frequently diagnosed late, it has emerged as a major cause 
of morbidity and mortality worldwide. Its development is associated with complications at microvascular (retinopathy, neuropathy, and nephropathy) and macrovascular (stroke, coronary disease, and myocardial infarction) levels, causing human suffering and significant costs in the context of the economics of global health. ${ }^{5}$

The frequency, severity, and progression of diabetic complications are related to hyperglycemia levels, associated metabolic disturbances, duration of disease, and exposure to risk factors, as well as to the genetic component. About $40 \%$ of patients diagnosed with diabetes develop late complications of the disease in various tissues, which are not always detected in time.

T2DM is a major risk factor for the development of cardiovascular disease (CVD), which is responsible for $50 \%-80 \%$ of deaths in people with T2DM, as well as for substantial morbidity and loss of quality of life. T2DM can lead to cardiovascular $(\mathrm{CV})$ damage in a number of ways. As T2DM progresses, the heart and blood vessels undergo changes that lead to a number of different CV complications. ${ }^{6}$ Although coronary artery disease (CAD) is two to three times more common in diabetic patients that in non-diabetic individuals, ${ }^{7}$ it is not the only CV complication. Several experimental, pathological, epidemiological, and clinical studies ${ }^{8-11}$ have shown an association between DM and cardiomyopathy, the latter being defined as functional and structural changes at the myocardium, independent of hypertension, CAD, or any other known cardiac disease, leading to heart failure. The term "diabetic cardiomyopathy" (DCM) was introduced in 1972 by Rubler et al ${ }^{12}$ based on postmortem observations of heart failure in diabetic patients free of detectable CAD, which was further confirmed in numerous other clinical studies. ${ }^{13,14}$ This fact suggests that diabetes can lead to cardiac muscle damage without the coexistence of other $\mathrm{CV}$ risk factors.

Diabetes is typically associated with multiple metabolic and physiologic abnormalities, such as hyperglycemia, peripheral insulin resistance, dyslipidemia, hypertension, and overweight or obesity, and the activation of multiple hormone and cytokine systems - all of which are known risk factors for cardiac failure. However, it remains unknown which factors are most important to the overall incidence of cardiac failure in diabetic patients.

Several cellular and molecular mechanisms have been proposed to contribute to the pathogenesis of DCM. In this review, the role of inflammation in DCM development and progression will be analyzed.

\section{Pathophysiology of DCM}

DCM, a distinct clinical entity, is currently viewed as a result of complex relationships between metabolic abnormalities that accompany diabetes and its cellular consequences, resulting in functional and structural changes in the myocardium that, in combination with other features, impair cardiac performance, ultimately resulting in cardiac failure (Figure 1)..$^{15,16}$

\section{Functional changes}

In many cases, it has been found that abnormalities of diastolic function may advertise the subsequent progressive deterioration of cardiac function. The noninvasive assessment of diastolic dysfunction mainly relies on Doppler studies of diastolic transmitral inflow, flow velocities, flow patterns, isovolumic relaxation time, and deceleration time, which are the most common criteria used in its evaluation. Numerous authors have suggested that the most frequent and earliest functional effect observed by echocardiography in type 2 diabetic hearts is impaired diastolic function. ${ }^{17,18}$

"Diastolic dysfunction" can be defined as a condition in which myocardial relaxation and filling are impaired and incomplete. It can manifest as reduced early diastolic filling, increased atrial filling, extended isovolumetric relaxation, and an increased number of supraventricular premature beats. ${ }^{19}$ There is also an increased left ventricular (LV) end-diastolic pressure and a decreased LV end-diastolic volume. ${ }^{20}$

It is important to note that the impairment of diastolic performance is nonspecific and frequently observed in many diseases, such as hypertension, hypertrophic cardiomyopathy, and $\mathrm{CAD}$, while systolic function remains intact. However, several investigators have shown that changes in diastolic function are common, even in diabetic animals ${ }^{21,22}$ and diabetic patients, ${ }^{23,24}$ without any clinical manifestations of congestive heart failure. Indeed, evidence of diastolic dysfunction has been found in patients with impaired glucose tolerance, ${ }^{25}$ with newly diagnosed diabetes or a short duration of disease, and free of microvascular complications. ${ }^{23}$ Thus, the detection of diastolic dysfunction may be a useful marker for the prognosis of cardiac mortality in diabetic subjects.

There are also studies ${ }^{26,27}$ that have reported an association between diabetes and changes in systolic function. "Systolic dysfunction" is defined as the loss of the heart's ability to pump arterial blood in the peripheral circulation and is associated with a reduction of the LV ejection fraction, fractional shortening, and cardiac output. These alterations of systolic function were proven in both human and animal models of T1DM and T2DM. ${ }^{28,29}$ However, Radovits et al 


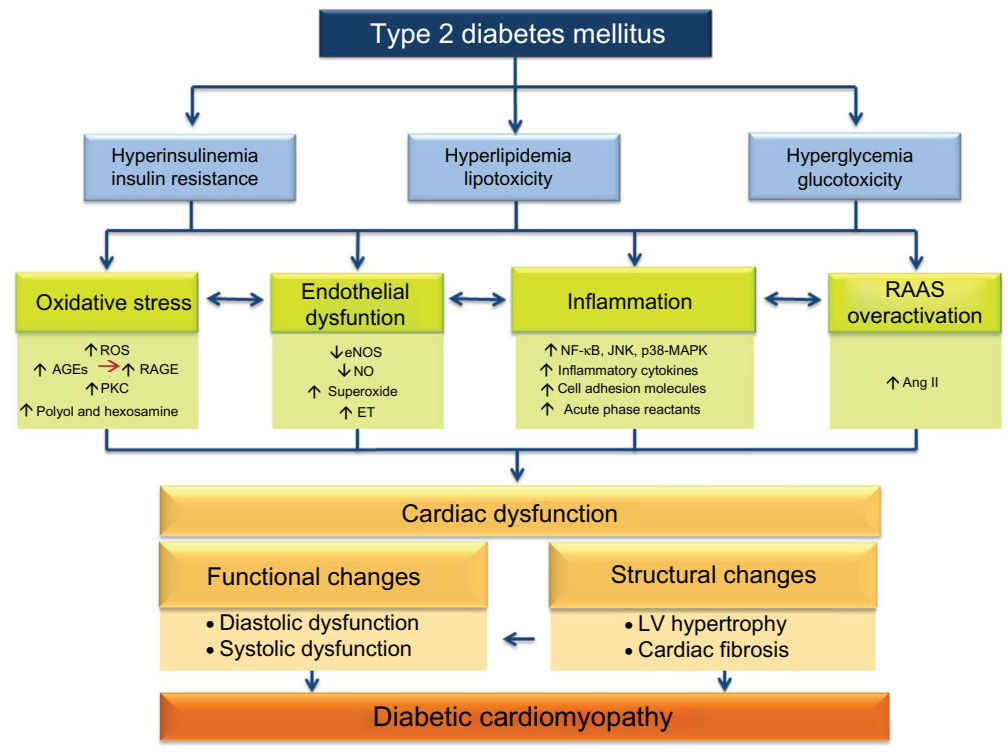

Figure I Metabolic and cellular abnormalities associated with type 2 diabetes mellitus that underlie the development of diabetic cardiomyopathy. Abbreviations: AGEs, advanced glycation end products; Ang II, angiotensin II; eNOS, endothelial nitric oxide synthase; ET, endothelin; JNK, c-jun NH2-terminal kinase; LV, left ventricular; NF- $\mathrm{KB}$, nuclear factor- $\mathrm{KB}$; NO, nitric oxide; PKC, protein kinase C; $338-\mathrm{MAPK}$, p38-mitogen-activated protein kinase; RAAS, renin-angiotensinaldosterone system; RAGE, receptor for AGEs; ROS, reactive oxygen species; TNF- $\alpha$, tumor necrosis factor-alpha.

suggest that systolic dysfunction may be more pronounced in type 1 DCM. ${ }^{30}$

In DCM, systolic dysfunction occurs late, often when patients have already developed significant diastolic dysfunction. The prognosis in patients with depressed systolic dysfunction is poor with an annual mortality of $15 \%-20 \%$. The presence of systolic dysfunction in the early years of diabetes is still controversial, while diastolic dysfunction is more easily detected by Doppler echocardiography. The controversy of the early existence of systolic dysfunction in diabetes is probably related to the fact that current techniques used for systolic function evaluation are less sensitive than those used for diastolic dysfunction assessment. For this reason, more sensitive techniques for systolic assessment have been developed, such as strain, strain rate, and myocardial tissue Doppler velocity, which have permitted the detection of preclinical systolic abnormalities in diabetic patients. ${ }^{31}$

\section{Structural changes}

A number of studies have shown structural changes in diabetic hearts in the absence of hypertension, CAD, and valvular heart diseases. One of the most important structural hallmarks of DCM is cardiac hypertrophy and this, in turn, is a powerful predictor of CV events (Figure 1).

Hypertrophy is a form of growth characterized by an increase in the average cell size of the constituting organ (in contrast to hyperplasia, in which the number of cells increases). Although LV hypertrophy (LVH) is more common, the right ventricle can also become enlarged or both may be affected. The common factor is that in physiological cardiac hypertrophy the intermittent load induces an increase in chamber wall thickness, which is compensated for by an increase in ventricular volume, thus balancing the wall thickness to chamber volume ratio. ${ }^{32}$ Numerous studies have shown that patients with T2DM have an increase in LVH independent of other confounding factors, including hypertension. ${ }^{33}$ In T2DM, LVH generally represents a more advanced stage of disease and may manifest after a longer period. The causes and mechanisms underlying LVH are poorly understood, and the predictive contribution of LVH to DCM is not entirely clear. Recently, however, clinical and animal studies have proposed evidences implicating the diabetic milieu of hyperinsulinemia, insulin resistance, hyperglycemia, and increased nonesterified fatty acids (FAs) in the pathophysiology of LVH in DM patients. For instance, insulin may act as a growth factor in the myocardium, which is supported by the experimental observation that sustained hyperinsulinemia leads to increased myocardial mass and decreased cardiac output in rats. ${ }^{34,35}$ Higher circulating levels of the hormone leptin have also been linked to the development of LVH in obese diabetic humans. ${ }^{36}$ The consistency of results demonstrates a clear impact of DM per se on increased LV mass that encompasses the development of diabetes-related LVH.

Another mechanism proposed to explain cardiac alterations in DCM is related to the development of myocardial 
fibrosis (Figure 1). Cardiac fibrosis is the accumulation of interstitial glycoproteins and increased extracellular collagen matrix, leading to increased stiffening and reduced relaxation of the ventricles. Interstitial and perivascular fibrosis with significant increase in collagen deposition has frequently been observed in heart biopsy samples from diabetic patients without significant CAD. ${ }^{37}$ Similar findings have also been observed in animal models of DM..$^{38,39}$

The echocardiographic features of increased LV fibrosis appear in the form of impaired relaxation and diastolic dysfunction and it has been suggested that collagen is a major determinant of ventricular stiffness. Consequently, alterations in collagen phenotype may play an important role in the impaired LV diastolic filling that is typical of DCM. ${ }^{37}$ In a study with prediabetic Otsuka-Long-Evans-Tokushima Fatty rats, there was a correlation between increased extracellular collagen content and decrease in early mitral peak flow (decreased E/A ratio). ${ }^{38}$ The accumulation of cardiac fibrosis in diabetes is believed to result from decreased degradation of glycosylated collagen by matrix metalloproteinases and, conversely, from excessive production of collagen by fibroblasts due to increased rennin-angiotensin-aldosterone system (RAAS) activation. ${ }^{15}$

In addition, an increased formation of advanced glycation end products (AGEs) has also been reported to occur in the myocardium of DM patients, as a result of hyperglycemia. ${ }^{40}$ It has been demonstrated that collagen is particularly susceptible to AGE cross-linking and this association not only leads to myocardial stiffness but also to impairment of collagen degradation, leading to further collagen accumulation or fibrosis. ${ }^{37,41}$ Furthermore, the impairment of LV diastolic function of patients with diabetes may be secondary to alterations in collagen structure, specifically, increased collagen cross-linking or AGEs, ${ }^{41}$ thus contributing to the myocardial fibrosis and decreased compliance characteristic of DCM.

\section{Molecular mechanisms}

It is important to highlight some of the key events involved in the pathophysiology of T2DM that are the most important mechanisms contributing to development of DCM. The pathophysiology of T2DM is characterized by peripheral insulin resistance, abnormal regulation of hepatic glucose production, and decline in $\beta$-cell function, leading to the eventual failure of these cells.

Initially, there is impaired insulin secretion, which causes a decrease in glucose uptake and, in many patients, is associated with insulin resistance, leading to hyperglycemia. A relative insulin deficiency usually arises due to the actions of insulin resistance in muscle, fat, and liver, as well as an inadequate response of pancreatic $\beta$-cells. Thus, the development of a sustained hyperinsulinemia is required to maintain the homeostasis of glucose. However, when the pancreatic $\beta$-cell adaptation, required to maintain hyperinsulinemia, fails, then hyperglycemia and DM develop.

\section{Myocardial hyperinsulinemia, insulin resistance, and lipotoxicity}

Insulin, an anabolic hormone produced by pancreatic $\beta$-cells, is primarily responsible for regulating blood glucose. Impaired insulin action (or insulin resistance) is characterized by reduced conventional biological actions of insulin to stimulate glucose uptake in peripheral tissues and inhibit the lipolysis of the adipose tissue and hepatic glucose production, which are major metabolic dysfunctions associated with the early stages of T2DM. Elevated plasma insulin and lipid levels can lead to numerous metabolic and pathophysiological derangements in various tissues, including the heart. Moreover, insulin, as a hormone that has a broad spectrum of biological actions, may play a role in the etiology of various $\mathrm{CV}$ complications, in particular when these actions are deregulated.

Insulin promotes a great number of metabolic and mitogenic responses, through a network of metabolic pathways highly and specifically regulated. Insulin receptor activation results in the tyrosine phosphorylation of different substrates, including insulin receptor substrate (IRS)-1 and $-2 .{ }^{42}$ These IRS proteins play a key role in insulin signal transmission, serving as templates for connecting a variety of proteins and lead to adaptation of the signaling cascade. Thus, the insulin signaling is initiated by its binding to a specific membrane receptor and, therefore, activation of two main signaling cascades: the phosphoinositide 3-kinase (PI3K) and the extracellular signal-regulated kinase/mitogen-activated protein kinase (MAPK) pathways.

The activation of the PI3K pathway increases serine phosphorylation of protein kinase $\mathrm{B}(\mathrm{Akt})$ and this permits the transport of glucose through the translocation of GLUT-4 protein to the cell membrane. The consequent activation of Akt results in translocation of glucose transporter GLUT-4 to the membrane, allowing the uptake of glucose by facilitated diffusion. GLUT-4 is primarily responsible for glucose uptake in humans. Then, the PI3K/Akt pathway plays an important role in the metabolic effects of insulin, ${ }^{43}$ mediates glucose uptake and, after activation, is associated with the development of physiological hypertrophy, while the extracellular signalregulated kinase/MAPK pathway is important in gene 
expression and cell growth and differentiation, mediating the pathological hypertrophy. ${ }^{44}$

LVH may be associated with insulin resistance. Therefore, in case of insulin resistance or chronic hyperinsulinemia, the phosphorylation and activation of $\mathrm{PI} 3 \mathrm{~K}$ is reduced and there is an insulin-induced activation of the MAPK pathway, which results in cardiac hypertrophy. It is known that activation of PI3K pathway results in increased endothelial nitric oxide synthase (eNOS) activity and nitric oxide (NO) production and that the activation of the MAPK pathway is involved in stimulation of a vasoconstrictor endothelin-1. In fact, this represents a mechanism associated with insulin resistance, thus contributing to endothelial dysfunction and an increase in blood pressure due to the impaired vasodilator action of insulin (Figure 1).

As mentioned, the state of insulin resistance involves a significant decrease of myocardial glucose uptake due to cellular depletion of glucose transporter proteins, GLUT-1 and GLUT-4. In addition, diabetic cardiomyocyte is also characterized by increased myocardial FA uptake and triglyceride levels. Free fatty acids (FFA), once inside the cell, are converted into acetyl coenzyme A derivatives that will activate the isoforms of protein kinase $\mathrm{C}$ (PKC), an intracellular enzyme with the ability to block the insulin signaling pathways which, in turn, will block the entire cascade of subsequent reactions preventing insulin action. ${ }^{45}$ In the presence of elevated levels of FFA, there is a competition of these with glucose as energy substrate, with a shift in energy production from $\beta$-oxidation of FFA, ${ }^{46}$ leading to decreased glucose utilization and oxidation, with increased glucose levels and release stimulation, increasing the amount of insulin and promoting an insulin resistance. ${ }^{47}$

The increase of FFA and its metabolism leads to intracellular accumulation of toxic FA intermediates, such as ceramide and diacylglycerol, as well as the formation of reactive oxygen species (ROS), which contribute to oxidative stress, cardiomyocyte apoptosis, and increased myocardial oxygen consumption, resulting in reduced myocardial high-energy reserves and impaired contractility, promoting mitochondrial uncoupling leading to decreased adenosine triphosphate (ATP) availability. ${ }^{48,49}$ Therefore, all these mechanisms may be involved with a reduced cardiac performance, thus contributing to the pathogenesis of DCM.

Furthermore, the cardiac lipotoxicity in DCM also involves the activation of transcription factors that further affect FA uptake and oxidation. Therefore, FFA intracellular deposition is responsible for the saturation of the mitochondrial capacity of oxidation, thus activating transcription factors, including the peroxisome proliferator-activated receptors (PPARs).
Although PPARs are key regulators of FA metabolism in the heart, recent studies have shown that cardiac overexpression of PPAR-alpha (PPAR $\alpha$ ) and PPAR-gamma (PPAR $\gamma)$ causes lipotoxic cardiomyopathy and steatotic cardiomyopathy. ${ }^{50,51}$ Myocardial steatosis is an important event in the first stages of DCM, contributing to the development of myocardial apoptosis and subsequent remodeling. Thus, modulation of PPARs might have a positive impact on DCM, as further discussed in this review.

\section{Hyperglycemia and glucotoxicity}

Hyperglycemia has been seen as a major cause of DCM, due to activation of several mechanisms leading to an increase in oxidative stress, which is defined as an imbalance between the production of ROS and antioxidant defense mechanisms.

ROS are chemical compounds that result from the activation or reduction of molecular oxygen or derivatives of the products of this reduction, such as the superoxide anion and hydroxyl radical. ${ }^{52}$ ROS may have harmful consequences for the heart cells, including DNA damage as well as apoptosis, which in turn may promote cardiac dysfunction leading to structural and functional abnormalities that are associated with DCM (Figure 1).

Hyperglycemia induces oxidative stress by several pathways, such as increased activation of the polyol and hexosamine pathways, increased formation of AGEs, and activation of classical isoforms of $\mathrm{PKC}$, which induce increased production of mitochondrial ROS, nonenzymatic glycation of proteins, and glucose auto-oxidation. Activation of these pathways corresponds to an increased glucotoxicity, which may cause cellular injury. They are also associated not only with the development of diabetic complications but also with insulin resistance and pancreatic $\beta$-cell dysfunction.

As already noted, the increase of AGEs is highly associated with myocardial fibrosis in diabetic hearts by affecting the structural components of the extracellular matrix, such as collagen, indicating the potential role of AGEs in DCM. ${ }^{53}$ AGEs are a heterogeneous group of proteins, lipids, and nucleic acids that are formed by nonenzymatic glycosylation. They bind to specific cell surface receptors (receptor for AGEs [RAGE]) and, in the cascade of intracellular signal transduction, form oxygen free radicals and promote the activation of gene expression. This receptor ligation increases the production of the transcription factor nuclear factor- $\kappa \mathrm{B}$ (NF- $\mathrm{KB}$ ), also causing increased oxidative stress.

The RAGE belongs to the immunoglobulin superfamily and binds to a wide variety of molecules, especially to ligands that are susceptible to aggregation and posttranslational modifications. 
This receptor is widely expressed in the peripheral and central nervous systems. A series of ligands of RAGE, as well as the activation of RAGE itself, can induce oxidative stress ${ }^{52}$ and exert direct effects on cardiac remodeling due to adhesive and growth-regulating properties.

In diabetes patients, elevated serum and tissue contents of AGEs have been found, which then activate RAGE. ${ }^{54,55}$ Further, in the heart tissues of diabetic rats, an increased expression of RAGE has been found, which seems to be associated with connective tissue growth factor. ${ }^{53}$ Overexpression of RAGE in diabetic hearts of animals implies a role for this receptor in mediating AGE-induced myocardial structural alterations.

In addition to AGE-induced fibrosis, several lines of evidence have suggested that AGE accumulation is associated with impaired calcium homeostasis and mitochondrial function and altered expression and function of both the ryanodine receptor and sarcoplasmic/endoplasmic reticulum $\mathrm{Ca} 2^{+}$-ATPase (SERCA), contributing to reduction of calcium entry in the myocyte and, consequently, impaired change myocardial contractility. ${ }^{56}$

PKC pathway activation is also correlated with biochemical changes underlying the development of DCM. These changes include increased vascular permeability and lead to blood vessel constriction and changes in blood flow, stimulating neovascularization, proliferation and apoptosis of endothelial cells, and the activation of several factors, such as transforming growth factor-beta, vascular endothelial growth factor, and insulin-like growth factor- $1 .^{57,58}$ Moreover, a recent study indicated that PKC promotes cardiac hypertrophy by activating NF- $\mathrm{\kappa B}$ (Figure 1). ${ }^{59}$

Endothelial dysfunction is also involved in the pathogenesis of DCM. The endothelium regulates the vascular tone by the releasing of vasodilator and vasoconstrictor substances; when released in an unbalanced way, endothelial dysfunction occurs. Endothelial dysfunction indicates the malfunction of the vascular endothelium and usually reflects a reduced bioavailability of NO, which is an important vasodilator. Furthermore, NO also has anti-hypertrophic, antiproliferative, and anti-inflammatory properties and inhibits leukocyte adhesion, limits adhesion and aggregation of platelets, and reduces the expression of plasminogen activator inhibitor 1 (PAI-1), a pro-thrombotic protein associated with vascular homeostasis. Diabetes is associated with decreased expression of eNOS and decreased production of NO through the inhibition of the IRS-PI3KAkt-eNOS-NO pathway. However, due to increased oxidative stress, an excess of NO becomes cytotoxic. Part of its toxicity is due to its reaction with superoxide, resulting in peroxynitrite formation and loss of NO bioavailability. ${ }^{60}$ This decreased NO bioavailability causes endothelial dysfunction leading to impaired vasodilatation. A relationship between the excessive cardiac production of ROS and endothelial dysfunction has been demonstrated in animal models of type 1 and $2 \mathrm{DM}$ and in humans with T2DM. ${ }^{61}$

\section{RAAS}

The RAAS is a hormonal cascade that plays a major role in the homeostatic control of arterial pressure by regulating blood vessel constriction. Deregulation of RAAS plays an important role in pathological origin of renal diseases, CVDs, and arterial hypertension and also contributes to the development of cardiomyopathy.

Activation of the RAAS, locally and systemically, is strongly associated with the development of insulin resistance and the onset of T2DM. ${ }^{62-64}$ In diabetes, excessive activation of the RAAS has been described. ${ }^{65,66}$ Now that it has been shown to be associated with some of the hallmarks of DCM, such as increased fibrosis, angiogenesis, oxidative damage, and cardiomyocyte and endothelial cell apoptosis and necrosis, this over activation has been recognized as an important factor in the progression of the disease. ${ }^{15,67}$

Angiotensin II (Ang II) is the main physiological effector molecule of RAAS; its release in the myocardium, due to the upregulation of RAAS, has diverse and widespread actions that affect cardiac function. ${ }^{68}$ Animal experiments have also shown that Ang II infusion induces insulin resistance ${ }^{69}$ and increased levels of Ang II and Type 1 receptors (AT1-R) have been shown in diabetic rats. ${ }^{70-72}$ Ang II can interfere with all intracellular signaling of insulin receptors, preventing the glucose receptor translocation, thus being one of the pathophysiologic bases of insulin resistance. AT1-R mediate most physiological and pathophysiological and deleterious effects attributed to Ang II. In the adult CV system, Ang II induces its vasoconstrictive effects on cardiomyocytes through ligand binding to the AT1R. ${ }^{73}$ The rise of Ang II in diabetic rats has been related to cardiomyocyte hypertrophy and apoptosis and it stimulates the proliferation of cardiac fibroblast and synthesis of collagen, causing myocardium interstitial and perivascular fibrosis, ventricular myocardium rigidity, and impaired diastolic function, leading to the clinical symptoms of DCM (Figure 1). ${ }^{74,75}$

\section{The role of inflammation in DCM}

Chronic low-grade inflammation is commonly associated with obesity and T2DM and clear evidence has emerged to 


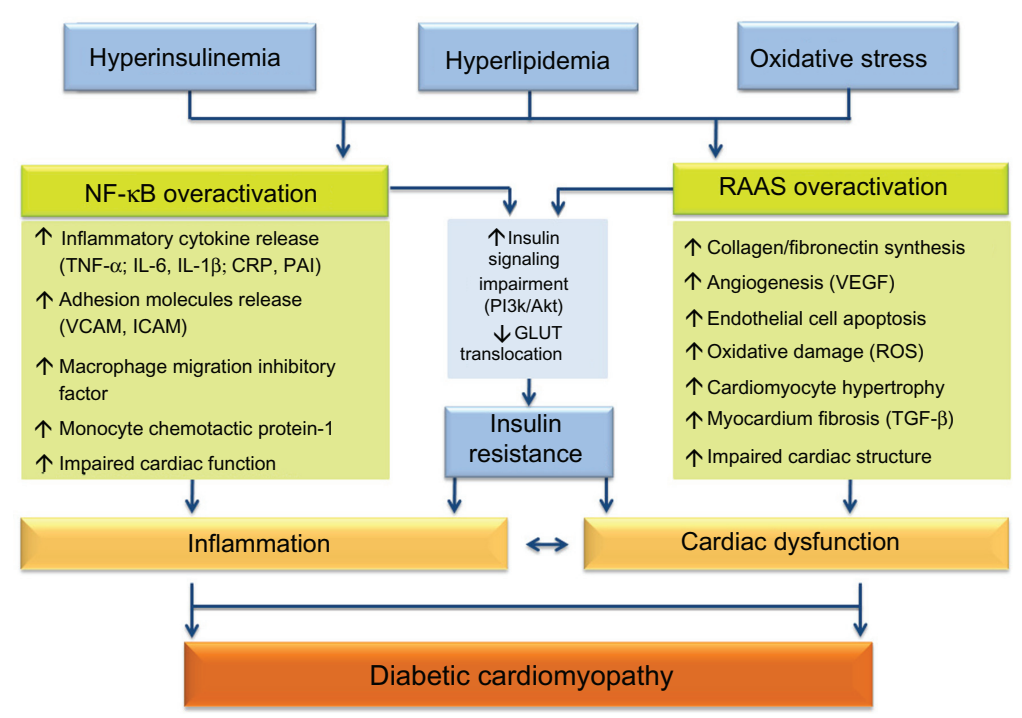

Figure 2 Cellular and molecular pathways that link inflammation with development of diabetic cardiomyopathy through over activation of the NF- $\mathrm{KB}$ pathway and reninangiotensin-aldosterone system.

Abbreviations: Akt, protein kinase B; CRP, C-reactive-protein; GLUT, glucose transporter proteins; ICAM, intracellular adhesion molecule; IL, interleukin; NF-אB, nuclear factor-KB; PAI, plasminogen activator inhibitor; PI3K, phosphoinositide 3-kinase; RAAS, renin-angiotensin-aldosterone system; ROS, reactive oxygen species; TGF- $\beta$, transforming growth factor-beta; TNF- $\alpha$, tumor necrosis factor-alpha; VCAM, vascular cell adhesion molecule; VEGF, vascular endothelial growth factor.

suggest that inflammatory process also contributes to the pathogenesis of DCM (Figure 2).

The activation of several signaling pathways, such as NF- $\kappa \mathrm{B}$, c-jun $\mathrm{NH}_{2}$-terminal kinase, or p38-MAPK, could mediate a state of inflammation, which is linked to insulin resistance, thus playing an important role in diabetic complications. ${ }^{76-78}$ In fact, NF- $\kappa \mathrm{B}$ represents one of the most important mediators of the inflammatory process. Activation of NF- $\mathrm{KB}$ is associated with the increased release of cytokines such as tumor necrosis factor-alpha (TNF- $\alpha$ ), which is often involved in cardiac damage and leads to $\mathrm{NF}-\kappa \mathrm{B}$ activation, thus contributing to the intensification of adverse effects in the diabetic heart. ${ }^{76}$ Elevated inflammatory mediators cause insulin resistance since they reduce the IRS-1 tyrosine phosphorylation, and the activation of PI3K and Akt, decreasing insulin signaling. ${ }^{79}$ Moreover, elevated inflammatory markers may exacerbate insulin deficiency by impairing $\beta$-cell function and inducing cell death, which implicate a progressive decline in $\beta$-cell mass. ${ }^{80}$

Elevated inflammatory cytokines, such as TNF- $\alpha$, interleukin (IL)-6, cell adhesion molecules, including vascular cell adhesion molecule-1 (VCAM-1) and intracellular adhesion molecule-1 (ICAM-1), acute phase reactants, such as C-reactive protein (CRP); PAI-1, and other biological markers of inflammation, have been found in circulation and in the diabetic hearts of T2DM patients. ${ }^{81,82}$ Accumulating data suggest that elevated levels of several inflammatory markers, such as IL1- $\beta$ and TNF- $\alpha$, are implicated in DCM, increase epicardial thickness, and promote myocyte contractile dysfunction, thus depressing myocardial function and contributing to heart failure. ${ }^{83}$ Moreover, cardiac overexpression of TNF- $\alpha$ has been associated with cardiac hypertrophy and fibrosis, as well with LV dysfunction (Figure 2). ${ }^{84,85}$ IL-6 has also been described as an inducer of myocardial damage. Therefore, excessive production of IL-6 can promote LV dysfunction and cardiac hypertrophy under acute myocardial infarction. ${ }^{86}$

Although the inflammatory response seems to be linked with DCM development, its presence and influence differs in the early and the long-standing stages of the disease. Therefore, according to Ares-Carrasco et al, ${ }^{87}$ using normotensive and spontaneously hypertensive rats (SHR) with T1DM induced by streptozotocin, myocardial fibrosis and apoptosis are features of myocardial damage secondary to long-term experimental diabetes, but inflammation was modulated by the expression of anti-inflammatory molecules, in particular IL-10, and antioxidants. The authors also found interesting effects when diabetes coexisted with hypertension. DCM and hypertensive cardiomyopathy share some typical features, including functional and structural changes that contribute to cardiac tissue impairment.

Further, according to the proteomics studies of AresCarrasco et al in SHR and SHR/DM1 rats, ${ }^{88}$ when diabetes and hypertension coexist, hearts present with impaired expression of metabolic, hypertrophic, and apoptotic proteins, in contrast with the early stages of injury, in which fibrotic and inflammatory rates are not additive. 
Furthermore, they suggest that in such a stage of diabetes and hypertension, PPAR $\alpha$ activation, as a compensatory response to the metabolic, apoptotic, and hypertrophic impairment, could reduce cardiac hypertrophy. In this sense, therapeutics with PPAR $\alpha$ agonists could have beneficial anti-hypertrophic effects on the hypertensive DCM. These interesting recent findings, using SHR rats without DM1 versus those with DM1, reinforce and expand previous suggestions in DM patients, in which the presence of hypertension increased the myocardial and vascular cell changes observed in the diabetic patients. ${ }^{89}$ Therefore, when diabetes and hypertension coexist, the DM-induced changes in the myocardial cells and capillaries lead to myocardial cell injury, interstitial fibrosis, and impairment of ventricular systolic and diastolic function. The additive effects of diabetes and hypertension might explain the beneficial effects of antihypertensive drugs - such as irbesartan, an angiotensin type 1 receptor antagonist - in a mouse model of streptozotocin-induced DCM. ${ }^{90}$ The use of irbesartan was able to attenuate cardiac failure due to reduction of inflammation and normalization of cardiac fibrosis.

As mentioned, hyperglycemia-induced oxidative stress is strongly correlated with the development of DCM. In fact, hyperglycemia has been shown to activate various oxidative stress-responsive/pro-inflammatory transcription factors, including NF- $\kappa \mathrm{B}$, to induce collagen and fibronectin synthesis, as well as to stimulate the production of inflammatory cytokines.

A recent study suggests that hyperglycemia-induced cardiomyocyte apoptosis is mediated by the production of monocyte chemotactic protein-1, providing a molecular link between hyperglycemia, inflammation, and DCM. ${ }^{91}$ Yu et al indicated that hyperglycemia-induced diastolic dysfunction may be mediated partly by the macrophage migration inhibitory factor, suggesting that the NF- $\mathrm{KB}$ pathway may be involved in this process. ${ }^{81}$ In addition, in this same study, the authors demonstrated the macrophage migration inhibitory factor effects in abnormal upregulation of $\mathrm{G}$ proteincoupled receptor kinase 2 , which may be associated with a constant activation of beta1-adrenergic receptor and heart failure development. Another factor that plays an important role in modulation of inflammation in DCM concerns the RAAS activation. Ang II not only induces vasoconstriction, cell growth, and oxidative stress but also stimulates inflammation. Ang II is able to induce cytokine release, ${ }^{92}$ also stimulating the production of PAI-1 and pro-inflammatory transcription factors, such as NF- $\kappa \mathrm{B},{ }^{93}$ which in turn regulate adhesion molecules (VCAM-1 and ICAM-1) and the expression of several cytokines, as already mentioned.

\section{Potential for anti-inflammatory therapeutics against DCM}

Although specific therapy for the treatment or prevention of DCM is still lacking, some therapeutic strategies may present potential benefits.

\section{Physical exercise}

Improvement of glycemic control is the most basic and important target for preventing diabetic heart disease, thus lifestyle and dietary modifications are very important in this regard. Increased regular physical activity has been shown to benefit glycemic control and improve insulin sensitivity, increase the metabolism of glucose and FAs in heart muscle and may improve LV function, thus attenuating diabetes-induced cardiac alterations. Physical exercise also has anti-inflammatory effects, as it decreases the release of inflammatory cytokines from the skeletal muscles, endothelial cells, and immune system and increases antiinflammatory cytokines, such as adiponectin. ${ }^{94}$ Using an animal model of T2DM, the Zucker Diabetic Fatty rat, our group has demonstrated that regular aerobic exercise not only improves glycemic control and attenuates dyslipidemia but also, as mentioned, promotes an anti-inflammatory effect by reducing pro-inflammatory cytokines, such as TNF- $\alpha$ and CRP, and increasing adiponectin levels. ${ }^{95-97}$ This effect occurs independently of weight loss and is not observed if an acute extenuating exercise is used. ${ }^{98}$ However, weight loss is also associated with a reduction of inflammatory mediators, including some cytokines and CRP. 99,100

\section{Antidiabetic agents}

\section{Insulin-sensitizing agents}

Insulin resistance is a hallmark of T2DM and plays an important role in the pathogenesis of DCM. Thus, agents used to ameliorate insulin resistance might be useful for the treatment or prevention of DCM. Many studies have indicated that insulin may be cardioprotective and one of the reasons that could contribute to this effect may be related to the antiinflammatory action of insulin itself. Several studies have shown a reduction of adhesion molecules, such as ICAM-1 and E-selectin, circulating CRP, IL-6, and PAI-1 due to insulin-sensitizing therapy. ${ }^{101,102}$

Metformin is one of the most commonly prescribed antidiabetic drugs and is known as an insulin-sensitizing 
agent. Metformin improves peripheral sensitivity to insulin and promotes intensive glucose control. ${ }^{103}$ Besides these properties, some studies have demonstrated the cardioprotective actions of metformin, since it can improve cardiac function and inhibit cardiac hypertrophy by stimulating adenosine monophosphateactivated protein kinase activity and preventing the structural and functional derangements in DCM. ${ }^{103-105}$ Metformin may also exert anti-inflammatory actions since it inhibits the cytokine-induced expression of pro-inflammatory and adhesion molecule genes by reducing NF- $\kappa \mathrm{B}$ activity and increasing Akt activation. ${ }^{106}$ However, the risk of lactic acidosis caused by metformin may be a contraindication for its use in diabetic patients with heart failure.

Thiazolidinediones (TZDs) and PPAR agonists are other insulin-sensitizing agents used in T2DM treatment, with proven ability to improve insulin sensitivity and glycemic control and to decrease FFA concentration. The possible beneficial effects of TZDs on the myocardium have been demonstrated in several studies. In animal models, TZDs may improve diabetic cardiac function by raising myocardial glucose uptake and reducing delivery of FAs to the myocardium. Kim et a ${ }^{107}$ have suggested that pioglitazone can prevent diastolic dysfunction in the hearts of rats with advanced diabetes by improving myocardial FA metabolism, while Tsuji et $\mathrm{al}^{108}$ have confirmed that pioglitazone improves LV diastolic function in prediabetic rats. The improvement of myocardial diastolic function was also observed in T2DM patients treated with rosiglitazone. ${ }^{109}$ In that study, the effect of rosiglitazone on cardiac function was associated with a decrease in oxidative stress and inflammation in these patients. Additionally, other factors have been noted as being involved in the improved cardiac function with the use of TZDs, including decreased collagen accumulation ${ }^{108}$ and consequent decreased fibrosis, ${ }^{110}$ as well as inhibition of cardiomyocyte hypertrophy. ${ }^{111}$ In contrast, some clinical and echocardiographic studies have shown that the use of TZDs does not appear to exert any beneficial or deleterious effect on the cardiac structure and function in patients with T2DM. ${ }^{112,113}$

Pioglitazone and rosiglitazone stimulate PPAR- $\gamma$, which regulates important genes for the metabolism of glucose and fat. Both agents enhance insulin sensitivity in skeletal muscle and adipose tissue via the activation of PPAR $\gamma .{ }^{114}$ However, activation of PPAR $\gamma$ in the myocardium may also have antiinflammatory effects. Takano et $\mathrm{al}^{115}$ demonstrated that PPAR activators inhibit TNF- $\alpha$ expression at the transcription level in part by attenuating NF- $\mathrm{KB}$ activity in cardiomyocytes. This finding was corroborated by Yamamoto et al in rat cardiac myocytes. ${ }^{111}$ However, the effects of this therapy on cardiac function in patients with T2DM have not yet been fully elucidated and there is increasing discussion about the application of these compounds due to their propensity for fluid retention and increasing the risk of congestive heart failure in susceptible patients. ${ }^{116,117}$

PPAR $\alpha$ is the most abundant isoform in the heart. Under ligand stimulation by FFA, PPAR $\alpha$ recruits specific co-activators, including, among other transcription factors, the peroxisome proliferator-activated receptor- $\alpha$ co-activator- $1 \alpha$ PGC1 $\alpha$, which regulates the genes involved in fuel homeostasis, as well as others. ${ }^{118}$ As cardiac overexpression of PPARs induces cardiac lipotoxicity and steatotic cardiomyopathy, which contributes to the development of myocardial apoptosis and hypertrophy/ remodeling, ${ }^{119-121}$ modulation of PPARs has been seen as a therapeutic opportunity for DCM management. In experimental DCM, a PPAR $\alpha$ agonist treatment ameliorated induced cardiac apoptosis and dysfunction. ${ }^{122,123}$ Ares-Carrasco et $\mathrm{al}^{88}$ evaluated the potential beneficial role of PPAR $\alpha$ activation in the associated hypertrophy in a rat model of chronic diabetes and hypertension. According to their findings, PPAR $\alpha$ could be activated for different responses to FFA degradation in stages when diabetes and hypertension coexists, attenuating the hypertrophy. Thus, PPAR $\alpha$-agonist therapy may prove a valid anti-hypertrophic measure; however, more research is required to fully understand the role of PPAR $\alpha$ agonists, as well as TZDs, in DCM.

\section{Incretin modulators}

The glucagon-like peptide-1 (GLP-1) is an incretin hormone rapidly released after food intake that exerts several actions that are important in maintaining glucose homeostasis, stimulating postprandial insulin secretion, and improving insulin sensitivity. It is noteworthy that in patients with obesity or T2DM, the postprandial levels of intact GLP-1 are significantly reduced compared with those in normal subjects.

The GLP-1 receptor has been described in extrapancreatic tissue, including the heart, which encouraged studies concerning its role in cardiac physiology, as well as the putative benefits of GLP-1 agonists in cardiac disorders. ${ }^{124,125}$ Experimental and clinical studies ${ }^{126-128}$ have suggested that GLP-1 agonists may have a considerable cardioprotective role in the myocardium, although the mechanisms through which GLP-1 acts have not yet been elucidated. GLP-1 attenuated myocardial ischemia-reperfusion injury in the in vitro rat heart and showed cardioprotective and inotropic effects in another study using isolated rat hearts. ${ }^{129,130}$ Furthermore, it has been shown that mice with the genetic deletion of the GLP-1 receptor display reduced heart rate, elevated LV 
end-diastolic pressure, and impaired LV contractility and diastolic function after insulin administration. In addition, infusion of GLP-1 resulted in improved LV function, hemodynamic status, and efficiency, indicating a direct role of GLP-1 in cardiac physiology. ${ }^{131}$

The pharmacologic use of GLP-1 receptor agonists has been shown to reduce body weight and systolic blood pressure and significantly improve glycemic control and lipid profile. Some studies ${ }^{132,133}$ have reported that GLP-1 and its agonists have antioxidant, vasoprotective, and antihypertensive effects as well as anti-inflammatory properties. One of these studies showed that the GLP-1 liraglutide exerts an anti-inflammatory effect on vascular endothelial cells through increased NO production and suppression of NF- $\mathrm{KB}$ activation, which is at least partly mediated via adenosine monophosphateactivated protein kinase activation. ${ }^{134}$ In a recent study using the same GLP-1 analog, cardiac hypertrophy was ameliorated in mice. ${ }^{135}$ However, further research is advised to better understand the complete benefits of GLP-1 agonists in the treatment of DCM.

Dipeptidyl peptidase 4 (DPP-4) inhibitors, such as sitagliptin, vildagliptin, and saxagliptin, are able to increase the endogenous contents of incretins such as GLP-1. Besides their effect on glycemic control, DPP-4 inhibitors, or gliptins, have been shown to have cyto-protective actions on other tissues, including on that of the heart, ${ }^{136,137}$ which might be due to anti-inflammatory and antioxidant properties. Our group has already shown in the Zucker Diabetic Fatty rat that sitagliptin treatment for 6 weeks, even at a low dose, is able to promote anti-inflammatory as well antioxidant effects. ${ }^{138,139}$

DPP-4 inhibitors have the advantage of being available for oral administration and do not raise the supraphysiological concentration of GLP-1; however, they do impede the formation of unspecific proteins (neuronal) and GLP-1 degradation products, which have been shown to have beneficial roles in the CV system.

Further research is needed to elucidate the importance of both these incretin modulators, DPP-IV inhibitors and GLP-1 analogs, in DCM therapy.

\section{Other non-antidiabetic agents}

\section{Statins}

The effectiveness of statin therapy in DCM has not yet been fully clarified, although there is some evidence of decreased mortality and lowered risk of $\mathrm{CV}$ events in diabetic patients treated with statins. ${ }^{140}$ Statins are primarily inhibitors of cholesterol biosynthesis; however, although the key benefits of statins were initially attributed to their lipid-lowering effects, it is now known that they act directly through other cellular mechanisms and these actions are known as "pleiotropic effects." 141,142 These effects are related to the improvement of endothelial function by mechanisms both dependent and independent of cholesterol. By the increased expression and activation of eNOS, producing an increase in the bioavailability of NO, they are also involved in reducing blood thrombogenicity, oxidative stress, and cell proliferation.

Statins may also exert anti-inflammatory effects by several pathways, ${ }^{143}$ including reduced activity of VCAM-1 and ICAM-1, decreased function and levels of monocyte chemotactic protein-1, and decreased CRP. Statins have been shown to inhibit pro-inflammatory pathways by reducing the levels and activities of transcription factors involved in inflammation. Some studies ${ }^{144,145}$ have shown that atorvastatin, for example, improves LV function, reduces fibrosis, and prevents cardiac hypertrophy. In addition, the protective effects of atorvastatin on cardiac remodeling were associated with the anti-inflammatory actions that atorvastatin can exert. ${ }^{146,147}$ However, further studies are required to better evaluate the possible beneficial effects of statins in DCM.

\section{RAAS inhibitors}

As already discussed, the activation of the RAAS and Ang II release are two important factors that contribute to the development of DCM. Thus, the inhibition of the RAAS seems to have beneficial cardioprotective effects.

Angiotensin-converting enzyme (ACE) inhibitors and angiotensin receptor blockers (ARBs) are the drugs most commonly used to block the RAAS and there is much evidence to suggest that these antihypertensive agents reduce $\mathrm{CV}$ mortality in diabetic patients. Indeed, it has been suggested that treatment with ACE inhibitors and ARBs could ameliorate diabetesinduced cardiac dysfunction and improve the outcome of heart failure in diabetic patients. ${ }^{148}$ Improved cardiac fibrosis, reduced collagen synthesis and deposition, reduced cardiomyocyte apoptosis, as well as prevention of cardiac hypertrophy, are some of the beneficial consequences at cardiac level resulting from treatment with ACE inhibitors and ARBs. ${ }^{15,149}$ It is known that aldosterone antagonists may also have similar beneficial effects on myocardial hypertrophy and fibrosis. ${ }^{150}$

Experimental and clinical studies also suggest that, beyond their function of reducing blood pressure, these drugs may contribute to the prevention of T2DM by improving insulin sensitivity, enhancing glucose uptake, improving pancreatic and skeletal muscle blood flow, and stimulating proliferation and differentiation of adipocytes. ${ }^{151,152}$ 
Ang II is a pro-inflammatory peptide and the inhibition of its production or action, using ACE inhibitors and ARBs, respectively, could result in an anti-inflammatory action. Several studies ${ }^{154,155}$ with ACE inhibitors and ARBs have showed decreases in various pro-inflammatory cytokines and oxidative stress, independent of their effects on blood pressure. ${ }^{153,155}$ For instance, ramipril, an ACE inhibitor, decreases the expression of TNF- $\alpha$, IL- 6 , and IFN- $\gamma$, as evident in LV biopsies, in unstable angina patients; ${ }^{156}$ the effect was similar when patients were treated with valsartan, an ARB. In contrast, Gullestad et al ${ }^{157}$ demonstrated that high-dose ACE inhibitor therapy - in this case, enalapril - is selective to reduction of IL-6 levels in circulation, which might be associated with the reduction of ventricular hypertrophy in patients with chronic heart failure. Candesartan, another ARB, also decreases plasma levels of TNF- $\alpha$, IL-6, and VCAM-1 in patients with heart failure. ${ }^{158}$ However, the studies, which included the anti-inflammatory effects of these drugs, were not conclusive and had controversial results. The effects depend on the type of inhibitor used, as well as the dosage levels and durations of the pharmacological treatment, thus further research is needed.

\section{Conclusion and future perspectives}

DCM is a specific cardiomyopathy that develops in diabetes patients, which is due to structural and functional abnormalities in the myocardium. Several lines of evidence suggest an important role for inflammation in the pathophysiology of DCM. Therefore, better understanding of the mechanisms underlying the inflammatory process will bring new opportunities for the prevention and/or treatment of DM and of its serious complications, including DCM. Currently, both non-pharmacological - such as physical exercise - and pharmacological measures, which include some antidiabetic agents, as well as other drugs, seem to have beneficial actions against the inflammation underlying DCM, but further research is advised to improve diagnosis, prevention, and treatment of this disorder.

\section{Disclosure}

The authors declare no conflicts of interest in this work.

\section{References}

1. George B, Cebioglu M, Yeghiazaryan K. Inadequate diabetic care: global figures cry for preventive measures and personalized treatment. EPMAJ. 2010;1(1):13-18.

2. Copeland KC, Becker D, Gottschalk M, Hale D. Type 2 diabetes in children and adolescents: risk factors, diagnosis, and treatment. Clinical Diabetes. 2005;23(4):181-185.
3. Wild S, Roglic G, Green A, Sicree R, King H. Global prevalence of diabetes: estimates for the year 2000 and projections for 2030. Diabetes Care. 2004;27(27):1047-1053.

4. International Diabetes Federation (IDF). IDF Diabetes Atlas. 4th ed. Brussels: IDF; 2010.

5. Fowler MJ. Microvascular and macrovascular complications of diabetes. Clinical Diabetes. 2008;26(2):77-82.

6. Tuomilehto J, Lindström J. The major diabetes prevention trials. Curr Diab Rep. 2003;3(2):115-122.

7. Fisher M. Diabetes: can we stop the time bomb? Heart. 2003;89 Suppl 2: ii28-ii30; discussion ii35-ii37.

8. Bäcklund T, Palojoki E, Saraste A, et al. Sustained cardiomyocyte apoptosis and left ventricular remodelling after myocardial infarction in experimental diabetes. Diabetologia. 2004;47(2):325-330.

9. Yang $\mathrm{ZH}$, Peng XD. Insulin resistance and heart injury in rats with insulin resistance or type 2 diabetes mellitus. Acta Cardiol. 2010;65(3):329-335.

10. Kannel WB, Hjortland M, Castelli WP. Role of diabetes in congestive heart failure: the Framingham study. Am J Cardiol. 1974;34(1):29-34.

11. Shindler DM, Kostis JB, Yusuf S, et al. Diabetes mellitus, a predictor of morbidity and mortality in the Studies of Left Ventricular Dysfunction (SOLVD) Trials and Registry. Am J Cardiol. 1996; 77(11):1017-1020.

12. Rubler S, Dlugash J, Yuceoglu YZ, Kumral T, Branwood AW, Grishman A. New type of cardiomyopathy associated with diabetic glomerulosclerosis. Am J Cardiol. 1972;30(6):595-602.

13. Galderisi M, Anderson KM, Wilson PW, Levy D. Echocardiographic evidence for the existence of a distinct diabetic cardiomyopathy (the Framingham Heart Study). Am J Cardiol. 1991;68(1):85-89.

14. Shrestha NR, Sharma SK, Karki P, Shrestha NK, Acharya P. Echocardiographic evaluation of diastolic function in asymptomatic type 2 diabetes. J Nepal Med Assoc. 2009;48(173):20-23.

15. Fang ZY, Prins JB, Marwick TH. Diabetic cardiomyopathy: evidence, mechanisms, and therapeutic implications. Endocr Rev. 2004;25(4): $543-567$.

16. Tziakas DN, Chalikias GK, Kaski JC. Epidemiology of the diabetic heart. Coron Artery Dis. 2005;16 Suppl 1:S3-S10.

17. Fang ZY, Yuda S, Anderson V, Short L, Case C, Marwick TH. Echocardiographic detection of early diabetic myocardial disease. J Am Coll Cardiol. 2003;41(4):611-617.

18. Karamitsos TD, Karvounis HI, Dalamanga EG, et al. Early diastolic impairment of diabetic heart: the significance of right ventricle. Int $J$ Cardiol. 2007;114(2):218-223.

19. Schannwell CM, Schneppenheim M, Perings S, Plehn G, Strauer BE. Left ventricular diastolic dysfunction as an early manifestation of diabetic cardiomyopathy. Cardiology. 2002;98(1-2):33-39.

20. Hamblin M, Friedman DB, Hill S, Caprioli RM, Smith HM, Hill MF. Alterations in the diabetic myocardial proteome coupled with increased myocardial oxidative stress underlies diabetic cardiomyopathy. $J \mathrm{Mol}$ Cell Cardiol. 2007;42(4):884-895.

21. Loganathan R, Bilgen M, Al-Hafez B, Alenezy MD, Smirnova IV. Cardiac dysfunction in the diabetic rat: quantitative evaluation using high resolution magnetic resonance imaging. Cardiovasc Diabetol. 2006;5:7.

22. Semeniuk LM, Kryski AJ, Severson DL. Echocardiographic assessment of cardiac function in diabetic $\mathrm{db} / \mathrm{db}$ and transgenic $\mathrm{db} / \mathrm{db}$-hGLUT4 mice. Am J Physiol Heart Circ Physiol. 2002;283(3):H976-H982.

23. Vanninen E, Mustonen J, Vainio P, Länsimies E, Uusitupa M. LV function and dimensions in newly diagnosed non-insulin-dependent diabetes mellitus. Am J Cardiol. 1992;70(3):371-378.

24. Boyer JK, Thanigaraj S, Schechtman KB, Perez JE. Prevalence of ventricular diastolic dysfunction in asymptomatic, normotensive patients with diabetes mellitus. Am J Cardiol. 2004;93(7): 870-875.

25. Celentano A, Vaccaro O, Tammaro P, et al. Early abnormalities of cardiac function in non-insulin-dependent diabetes mellitus and impaired glucose tolerance. Am J Cardiol. 1995;76(16):1173-1176. 
26. Andersen NH, Poulsen SH, Helleberg K, Ivarsen P, Knudsen ST, Mogensen CE. Impact of essential hypertension and diabetes mellitus on left ventricular systolic and diastolic performance. Eur J Echocardiogr. 2003;4(4):306-312.

27. Ballo P, Cameli M, Mondillo S, et al. Impact of diabetes and hypertension on left ventricular longitudinal systolic function. Diabetes Res Clin Pract. 2010;90(2):209-215.

28. Mihm MJ, Seifert JL, Coyle CM, Bauer JA. Diabetes related cardiomyopathy time dependent echocardiographic evaluation in an experimental rat model. Life Sci. 2001;69(5):527-542.

29. Mytas DZ, Stougiannos PN, Zairis MN, Foussas SG, Pyrgakis VN, Kyriazis IA. Diabetic myocardial disease: pathophysiology, early diagnosis and therapeutic options. J Diabetes Complications. 2009; 23(4):273-282.

30. Radovits T, Korkmaz S, Loganathan S, et al. Comparative investigation of the left ventricular pressure-volume relationship in rat models of type 1 and type 2 diabetes mellitus. Am J Physiol Heart Circ Physiol. 2009;297(1):H125-H133.

31. Murarka S, Movahed MR. Diabetic cardiomyopathy. J Card Fail. 2010; 16(12):971-979.

32. Dorn GW 2nd. The fuzzy logic of physiological cardiac hypertrophy. Hypertension. 2007;49(5):962-970.

33. Devereux RB, Roman MJ, Parancias M, et al. Impact of diabetes on cardiac structure and function: the strong heart study. Circulation. 2000; 101(19):2271-2276.

34. Karason K, Sjöström L, Wallentin I, Peltonen M. Impact of blood pressure and insulin on the relationship between body fat and left ventricular structure. Eur Heart J. 2003;24(16):1500-1505.

35. Holmäng A, Yoshida N, Jennische E, Waldenström A, Björntorp P. The effects of hyperinsulinaemia on myocardial mass, blood pressure regulation and central haemodynamics in rats. Eur J Clin Invest. 1996;26(11): 973-978.

36. Barouch LA, Berkowitz DE, Harrison RW, O’Donnell CP, Hare JM. Disruption of leptin signaling contributes to cardiac hypertrophy independently of body weight in mice. Circulation. 2003;108(6):754-759.

37. van Heerebeek L, Hamdani N, Handoko ML, et al. Diastolic stiffness of the failing diabetic heart: importance of fibrosis, advanced glycation end products, and myocyte resting tension. Circulation. 2008;117(1):43-51.

38. Mizushige K, Yao L, Noma T, et al. Alteration in left ventricular diastolic filling and accumulation of myocardial collagen at insulinresistant prediabetic stage of a type II diabetic rat model. Circulation. 2000;101(8):899-907.

39. Tschöpe C, Walther T, Königer J, et al. Prevention of cardiac fibrosis and left ventricular dysfunction in diabetic cardiomyopathy in rats by transgenic expression of the human tissue kallikrein gene. FASEB J. 2004;18(7):828-835.

40. Basta G, Schmidt AM, De Caterina R. Advanced glycation end products and vascular inflammation: implications for accelerated atherosclerosis in diabetes. Cardiovasc Res. 2004;63(4):582-592.

41. Aronson D. Cross-linking of glycated collagen in the pathogenesis of arterial and myocardial stiffening of aging and diabetes. $J$ Hypertens. 2003;21(1):3-12.

42. Brüning JC, Winnay J, Cheatham B, Kahn CR. Differential signaling by insulin receptor substrate 1 (IRS-1) and IRS-2 in IRS-1-deficient cells. Mol Cell Biol. 1997;17(3):1513-1521.

43. Zecchin HG, Carvalheira JB, Saad MJ. Mecanismos moleculares de resistência à insulina na síndrome metabólica [Molecular mechanisms of insulin resistance in metabolic syndrome]. Rev Soc Cardiol Estado de São Paulo. 2004;14(4):574-589. Portuguese.

44. Muniyappa R, Montagnani M, Koh KK, Quon MJ. Cardiovascular actions of insulin. Endocr Rev. 2007;28(5):463-491.

45. Perseghin J, Petersen K, Shulman G. Cellular mechanism of insulin resistance: potential links with inflammation. Int J Obes Relat Metab Disord. 2003;27 Suppl 3:S6-S11.

46. Rodrigues B, Cam MC, McNeill JH. Metabolic disturbances in diabetic cardiomyopathy. Mol Cell Biochem. 1998;180(1-2):53-57.

47. Poitout V, Robertson RP. Minireview: Secondary beta-cell failure in type 2 diabetes - a convergence of glucotoxicity and lipotoxicity. Endocrinology. 2002;143(2):339-342.
48. Khullar M, Al-Shudiefat AA, Ludke A, Binepal G, Singal PK. Oxidative stress: a key contributor to diabetic cardiomyopathy. Can J Physiol Pharmacol. 2010;88(3):233-240.

49. Eckel J, Reinauer H. Insulin action on glucose transport in isolated cardiac myocytes: signalling pathways and diabetes-induced alterations. Biochem Soc Trans. 1990;18(6):1125-1127.

50. Finck BN, Han X, Courtois M, et al. A critical role for PPARalphamediated lipotoxicity in the pathogenesis of diabetic cardiomyopathy: modulation by dietary fat content. Proc Natl Acad Sci U S A. 2003; 100(3):1226-1231.

51. Son NH, Park TS, Yamashita H, et al. Cardiomyocyte expression of PPARgamma leads to cardiac dysfunction in mice. J Clin Invest. 2007; 117(10):2791-2801.

52. Irani K. Oxidant signaling in vascular cell growth, death, and survival: a review of the roles of reactive oxygen species in smooth muscle and endothelial cell mitogenic and apoptotic signaling. Circ Res. 2000; 87(3):179-183.

53. Candido R, Forbes JM, Thomas MC, et al. A breaker of advanced glycation end products attenuates diabetes-induced myocardial structural changes. Circ Res. 2003;92(7):785-792.

54. Yamagishi S, Matsui T, Nakamura K. Kinetics, role and therapeutic implications of endogenous soluble form of receptor for advanced glycation end products (sRAGE) in diabetes. Curr Drug Targets. 2007; 8(10):1138-1143.

55. Yan SF, D'Agati V, Schmidt AM, Ramasamy R. Receptor for Advanced Glycation Endproducts (RAGE): a formidable force in the pathogenesis of the cardiovascular complications of diabetes \& aging. Curr Mol Med. 2007;7(8):699-710.

56. Bidasee KR, Nallani K, Yu Y, et al. Chronic diabetes increases advanced glycation end products on cardiac ryanodine receptors/calcium-release channels. Diabetes. 2003;52(7):1825-1836.

57. Koya D, King GL. Protein kinase C activation and the development of diabetic complications. Diabetes. 1998;47(6):859-866.

58. Das Evcimen N, King GL. The role of protein kinase C activation and the vascular complications of diabetes. Pharmacol Res. 2007;55(6): 498-510.

59. Min W, Bin ZW, Quan ZB, Hui ZJ, Sheng FG. The signal transduction pathway of PKC/NF-kappa B/c-fos may be involved in the influence of high glucose on the cardiomyocytes of neonatal rats. Cardiovasc Diabetol. 2009;8:8.

60. Yu Q, Gao F, Ma XL. Insulin says NO to cardiovascular disease. Cardiovasc Res. 2011;89(3):516-524.

61. Guzik TJ, Mussa S, Gastaldi D, et al. Mechanisms of increased vascular superoxide production in human diabetes mellitus: role of $\mathrm{NAD}(\mathrm{P}) \mathrm{H}$ oxidase and endothelial nitric oxide synthase. Circulation. 2002;105(14):1656-1662.

62. Niklason A, Hedner T, Niskanen L, Lanke J; Captopril Prevention Study Group. Development of diabetes is retarded by ACE inhibition in hypertensive patients - a subanalysis of the Captopril Prevention Project (CAPPP). J Hypertens. 2004;22(3):645-652.

63. de Kloet AD, Krause EG, Woods SC. The renin angiotensin system and the metabolic syndrome. Physiol Behav. 2010;100(5):525-534.

64. Abuissa H, Jones PG, Marso SP, O'Keefe JH Jr. Angiotensin-converting enzyme inhibitors or angiotensin receptor blockers for prevention of type 2 diabetes: a meta-analysis of randomized clinical trials. J Am Coll Cardiol. 2005;46(5):821-826.

65. Hayashi T, Takai S, Yamashita C. Impact of the renin-angiotensinaldosterone-system on cardiovascular and renal complications in diabetes mellitus. Curr Vasc Pharmacol. 2010;8(2):189-197.

66. McGuire DK, Winterfield JR, Rytlewski JA, Ferrannini E. Blocking the renin-angiotensin-aldosterone system to prevent diabetes mellitus. Diab Vasc Dis Res. 2008;5(1):59-66.

67. Privratsky JR, Wold LE, Sowers JR, Quinn MT, Ren J. AT1 blockade prevents glucose-induced cardiac dysfunction in ventricular myocytes: role of the AT1 receptor and NADPH oxidase. Hypertension. 2003;42(2):206-212.

68. Fyhrquist F, Saijonmaa O. Renin-angiotensin system revisited. J Intern Med. 2008;264(3):224-236. 
69. Richey JM, Ader M, Moore D, Bergman RN. Angiotensin II induces insulin resistance independent of changes in interstitial insulin. Am J Physiol. 1999;277(5 Pt 1):E920-E926.

70. Singh VP, Le B, Khode R, Baker KM, Kumar R. Intracellular angiotensin II production in diabetic rats is correlated with cardiomyocyte apoptosis, oxidative stress, and cardiac fibrosis. Diabetes. 2008;57(12):3297-3306.

71. Lee JH, Xia S, Ragolia L. Upregulation of AT2 receptor and iNOS impairs angiotensin II-induced contraction without endothelium influence in young normotensive diabetic rats. Am J Physiol Regul Integr Comp Physiol. 2008;295(1):R144-R154.

72. Siddiqui AH, Hussain T. EnhancedAT1 receptor-mediated vasocontractile response to ANG II in endothelium-denuded aorta of obese Zucker rats. Am J Physiol Heart Circ Physiol. 2007;292(4):H1722-H1727.

73. Fiordaliso F, Li B, Latini R, et al. Mycocyte death in streptozotocininduced diabetes in rats is angiotensin II-dependent. Lab Invest. 2000;80(4):513-527.

74. Brilla CG, Scheer C, Rupp H. Renin-angiotensin system and myocardial collagen matrix: modulation of cardiac fibroblast function by angiotensin II type 1 receptor antagonism. J Hypertens Suppl. 1997;15(6):S13-S19.

75. Dostal DE, Booz GW, Baker KM. Regulation of angiotensinogen gene expression and protein in neonatal rat cardiac fibroblasts by glucocorticoid and beta-adrenergic stimulation. Basic Res Cardiol. 2000;95(6):485-490.

76. Lorenzo O, Picatoste B, Ares-Carrasco S, Ramírez E, Egido J, Tuñón J. Potential role of nuclear factor $\kappa \mathrm{B}$ in diabetic cardiomyopathy. Mediators Inflamm. 2011:652097.

77. Kaneto H, Nakatani Y, Kawamori D, Miyatsuka T, Matsuoka TA. Involvement of oxidative stress and the JNK pathway in glucose toxicity. Rev Diabet Stud. 2004;1(4):165-174.

78. Li G, Barrett EJ, Barrett MO, Cao W, Liu Z. Tumor necrosis factor-alpha induces insulin resistance in endothelial cells via a p38 mitogen-activated protein kinase-dependent pathway. Endocrinology. 2007;148(7): 3356-3363.

79. Jager J, Grémeaux T, Cormont M, Le Marchand-Brustel Y, Tanti JF. Interleukin-1beta-induced insulin resistance in adipocytes through downregulation of insulin receptor substrate-1 expression. Endocrinology. 2007;148(1):241-251.

80. Donath MY, Størling J, Maedler K, Mandrup-Poulsen T. Inflammatory mediators and islet beta-cell failure: a link between type 1 and type 2 diabetes. J Mol Med (Berl). 2003;81(8):455-470.

81. Yu XY, Chen HM, Liang JL, et al. Hyperglycemic myocardial damage is mediated by proinflammatory cytokine: macrophage migration inhibitory factor. PLoS One. 2011;6(1):e16239.

82. Mano Y, Anzai T, Kaneko H, et al. Overexpression of human $\mathrm{C}$-reactive protein exacerbates left ventricular remodeling in diabetic cardiomyopathy. Circ J. 2011;75(7):1717-1727.

83. Westermann D, Rutschow S, Van Linthout $S$, et al. Inhibition of p38 mitogen-activated protein kinase attenuates left ventricular dysfunction by mediating pro-inflammatory cardiac cytokine levels in a mouse model of diabetes mellitus. Diabetologia. 2006;49(10):2507-2513.

84. Yokoyama T, Nakano M, Bednarczyk JL, McIntyre BW, Entman ML, Mann DL. Tumor necrosis factor- $\alpha$ provokes a hypertrophic growth response in adult cardiac myocytes. Circulation. 1997;95(5): 1247-1252.

85. Sun M, Dawood F, Wen WH, et al. Excessive tumor necrosis factor activation after infarction contributes to susceptibility of myocardial rupture and left ventricular dysfunction. Circulation. 2004;110(20):3221-3228.

86. Younce CW, Wang K, Kolattukudy PE. Hyperglycemia-induced cardiomyocyte death is mediated via MCP-1 production and induction of a novel zinc-finger protein MCPIP. Cardiovas Res. 2010;87: 665-674.

87. Ares-Carrasco S, Picatoste B, Benito-Martín A, et al. Myocardial fibrosis and apoptosis, but not inflammation, are present in longterm experimental diabetes. Am J Physiol Heart Circ Physiol. 2009;297(6):H2109-H2119.

88. Ares-Carrasco S, Picatoste B, Camafeita E, et al. Proteome changes in the myocardium of experimental chronic diabetes and hypertension: role of PPAR $\alpha$ in the associated hypertrophy. J Proteomics. 2012;75(6): 1816-1829.
89. Kawaguchi M, Techigawara M, Ishihata T, et al. A comparison of ultrastructural changes on endomyocardial biopsy specimens obtained from patients with diabetes mellitus with and without hypertension. Heart Vessels. 1997;12(6):267-274.

90. Westermann D, Rutschow S, Jäger S, et al. Contributions of inflammation and cardiac matrix metalloproteinase activity to cardiac failure in diabetic cardiomyopathy: the role of angiotensin type 1 receptor antagonism. Diabetes. 2007;56(3):641-646.

91. Kaneko K, Kanda T, Yokoyama T, et al. Expression of interleukin-6 in the ventricles and coronary arteries of patients with myocardial infarction. Res Commun Mol Pathol Pharmacol. 1997;97(1):3-12.

92. Schieffer B, Luchtefeld M, Braun S, Hilfiker A, Hilfiker-Kleiner D, Drexler H. Role of NAD(P)H oxidase in angiotensin II-induced JAK/STAT signaling and cytokine induction. Circ Res. 2000;87(12): 1195-1201.

93. Hernández-Presa M, Bustos C, Ortego M, et al. Angiotensin-converting enzyme inhibition prevents arterial nuclear factor- $\kappa \mathrm{B}$ activation, monocyte chemoattractant protein-1 expression and macrophage infiltration in a rabbit model of early accelerated atherosclerosis. Circulation. 1997;95(6):1532-1541.

94. Hopps E, Canino B, Caimi G. Effects of exercise on inflammation markers in type 2 diabetic subjects. Acta Diabetol. 2011;48(3):183-189.

95. de Lemos ET, Reis F, Baptista S, et al. Exercise training is associated with improved levels of C-reactive protein and adiponectin in ZDF (type 2) diabetic rats. Med Sci Monit. 2007;13(8):BR168-BR174.

96. Teixeira de Lemos E, Reis F, Baptista S, et al. Exercise training decreases proinflammatory profile in Zucker diabetic (type 2) fatty rats. Nutrition. 2009;25(3):330-339.

97. Teixeira-Lemos E, Nunes S, Teixeira F, Reis F. Regular physical exercise training assists in preventing type 2 diabetes development: focus on its antioxidant and anti-inflammatory properties. Cardiovasc Diabetol. 2011;10:12.

98. Teixeira de Lemos E, Pinto R, Oliveira J, et al. Differential effects of acute (extenuating) and chronic (training) exercise on inflammation and oxidative stress status in an animal model of type 2 diabetes mellitus. Mediators Inflamm. 2011;2011:253061.

99. Ziccardi P, Nappo F, Giugliano G, et al. Reduction of inflammatory cytokine concentrations and improvement of endothelial functions in obese women after weight loss over one year. Circulation. 2002;105(7): 804-809.

100. Tchernof A, Nolan A, Sites CK, Ades PA, Poehlman ET. Weight loss reduces $C$-reactive protein levels in obese postmenopausal women. Circulation. 2002;105(5):564-569

101. Mao XM, Liu H, Tao XJ, Yin GP, Li Q, Wang SK. Independent antiinflammatory effect of insulin in newly diagnosed type 2 diabetes. Diabetes Metab Res Rev. 2009;25(5):435-441.

102. Dandona P, Chaudhuri A, Ghanim H, Mohanty P. Insulin as an antiinflammatory and antiatherogenic modulator. JAm Coll Cardiol. 2009; 53(Supp1 5):S14-S20.

103. Effect of intensive blood-glucose control with metformin on complications in overweight patients with type 2 diabetes (UKPDS 34). UK Prospective Diabetes Study (UKPDS) Group. Lancet. 1998; 352(9131):854-865.

104. Gundewar S, Calvert JW, Jha S, et al. Activation of AMP-activated protein kinase by metformin improves left ventricular function and survival in heart failure. Circ Res. 2009;104(3):403-411.

105. Xie Z, Lau K, Eby B, et al. Improvement of cardiac functions by chronic metformin treatment is associated with enhanced cardiac autophagy in diabetic OVE26 mice. Diabetes. 2011;60(6):1770-1778.

106. Caballero AE, Delgado A, Aguilar-Salinas CA, et al. The differential effects of metformin on markers of endothelial activation and inflammation in subjects with impaired glucose tolerance: a placebocontrolled randomized clinical trial. J Clin Endocrinol Metab. 2004; 89(8):3943-3948.

107. Kim SK, Zhao ZS, Lee YJ, et al. Left-ventricular diastolic dysfunction may be prevented by chronic treatment with PPAR-alpha or -gamma agonists in a type 2 diabetic animal model. Diabetes Metab Res Rev. 2003;19(6):487-493. 
108. Tsuji T, Mizushige K, Noma T, et al. Pioglitazone improves left ventricular diastolic function and decreases collagen accumulation in prediabetic stage of a type II diabetic rat. J Cardiovasc Pharmacol. 2001;38(6):868-874.

109. Bibra HV, Diamant M, Scheffer PG, Siegmund T, Schumm-Draeger PM. Rosiglitazone, but not glimepiride, improves myocardial diastolic function in association with reduction in oxidative stress in type 2 diabetic patients without overt heart disease. Diabetes Vasc Dis Res. 2008;5(4):310-318.

110. Terui G, Goto T, Katsuta M, Aoki I, Ito H. Effect of pioglitazone on left ventricular diastolic function and fibrosis of type III collagen in type 2 diabetic patients. $J$ Cardiol. 2009;54(1):52-58.

111. Yamamoto K, Ohki R, Lee RT, Ikeda U, Shimada K. Peroxisome proliferator-activated receptor gamma activators inhibit cardiac hypertrophy in cardiac myocytes. Circulation. 2001;104(14): 1670-1675.

112. Dargie HJ, Hildebrandt PR, Riegger GA, et al. A randomized, placebo-controlled trial assessing the effects of rosiglitazone on echocardiographic function and cardiac status in type 2 diabetic patients with New York Heart Association Functional Class I or II Heart Failure. J Am Coll Cardiol. 2007;49(16):1696-1704.

113. Naka KK, Pappas K, Papathanassiou K, et al. Lack of effects of pioglitazone on cardiac function in patients with type 2 diabetes and evidence of left ventricular diastolic dysfunction: a tissue doppler imaging study. Cardiovasc Diabetol. 2010;9:57.

114. Hayat SA, Patel B, Khattar RS, Malik RA. Diabetic cardiomyopathy: mechanisms, diagnosis and treatment. Clin Sci (Lond). 2004; 107(6):539-557.

115. Takano H, Nagai T, Asakawa M, et al. Peroxisome proliferator-activated receptor activators inhibit lipopolysaccharide-induced tumor necrosis factor-alpha expression in neonatal rat cardiac myocytes. Circ Res. 2000;87(7):596-602.

116. Nesto RW, Bell D, Bonow RO, et al; American Heart Association; American Diabetes Association. Thiazolidinedione use, fluid retention, and congestive heart failure: a consensus statement from the American Heart Association and the American Diabetes Association. Circulation. October 7, 2003;108(23):2941-2948.

117. Cheng AY, Fantus IG. Thiazolidinedione-induced congestive heart failure. Ann Pharmacother. 2004;38(5):817-820.

118. Finck BN, Kelly DP. PGC-1 coactivators: inducible regulators of energy metabolism in health and disease. J Clin Invest. 2006;116(3): 615-622.

119. Leroy C, Tricot S, Lacour B, Grynberg A. Protective effect of eicosapentaenoic acid on palmitate-induced apoptosis in neonatal cardiomyocytes. Biochim Biophys Acta. 2008;1781(11-12):685-693.

120. Bishopric NH, Andreka P, Slepak T, Webster KA. Molecular mechanisms of apoptosis in the cardiac myocyte. Curr Opin Pharmacol. 2001;1(2):141-150.

121. Lee SD, Kuo WW, Lin JA, et al. Effects of long-term intermittent hypoxia on mitochondrial and Fas death receptor dependent apoptotic pathways in rat hearts. Int J Cardiol. 2007;116(3):348-356.

122. Baraka A, AbdelGawad H. Targeting apoptosis in the heart of streptozotocin-induced diabetic rats. $J$ Cardiovasc Pharmacol Ther. 2010;15(2):175-181.

123. Pérez-Pérez R, Ortega-Delgado FJ, García-Santos E, et al. Differential proteomics of omental and subcutaneous adipose tissue reflects their unalike biochemical and metabolic properties. J Proteome Res. 2009; 8(4):1682-1693.

124. Anagnostis P, Athyros VG, Adamidou F, et al. Glucagon-like peptide-1based therapies and cardiovascular disease: looking beyond glycaemic control. Diabetes Obes Metab. 2011;13(4):302-312.

125. Cobble ME, Frederich R. Saxagliptin for the treatment of type 2 diabetes mellitus: assessing cardiovascular data. Cardiovasc Diabetol. 2011;11:6.

126. Noyan-Ashraf MH, Momen MA, Ban K, et al. GLP-1R agonist liraglutide activates cytoprotective pathways and improves outcomes after experimental myocardial infarction in mice. Diabetes. 2009;58(4):975-983.
127. Saraceni C, Broderick TL. Effects of glucagon-like peptide-1 and longacting analogues on cardiovascular and metabolic function. Drugs $R$ D. 2007;8(3):45-53.

128. Ravassa S, Zudaire A, Díez J. GLP-1 and cardioprotection: from bench to bedside. Cardiovasc Res. 2012;94(2):316-323.

129. Bose AK, Mocanu MM, Carr RD, Yellon DM. Myocardial ischaemiareperfusion injury is attenuated by intact glucagon like peptide-1 (GLP-1) in the in vitro rat heart and may involve the $\mathrm{p} 70 \mathrm{~s} 6 \mathrm{~K}$ pathway. Cardiovasc Drugs Ther. 2007;21(4):253-256.

130. Ossum A, van Deurs U, Engstrøm T, Jensen JS, Treiman M. The cardioprotective and inotropic components of the postconditioning effects of GLP-1 and GLP-1 (9-36) a in an isolated rat heart. Pharmacol Res. 2009;60(5):411-417.

131. Hansotia T, Drucker DJ. GIP and GLP-1 as incretin hormones: lessons from single and double incretin receptor knockout mice. Regul Pept. 2005;128(2):125-134

132. Yamagishi S, Matsui T. Pleiotropic effects of glucagon-like peptide-1 (GLP-1)-based therapies on vascular complications in diabetes. Curr Pharm Des. 2011;17(38):4379-4385.

133. Vergès B, Bonnard C, Renard E. Beyond glucose lowering: glucagonlike peptide-1 receptor agonists, body weight and the cardiovascular system. Diabetes Metab. 2011;37(6):477-488.

134. Hattori Y, Jojima T, Tomizawa A, et al. A glucagon-like peptide-1 (GLP-1) analogue, liraglutide, upregulates nitric oxide production and exerts anti-inflammatory action in endothelial cells. Diabetologia. 2010;53(10):2256-2263.

135. Mells JE, Fu PP, Sharma S, et al. Glp-1 analog, liraglutide, ameliorates hepatic steatosis and cardiac hypertrophy in C57BL/6J mice fed a Western diet. Am J Physiol Gastrointest Liver Physiol. 2012;302(2): G225-G235.

136. Gomez N, Touihri K, Matheeussen V, et al. Dipeptidyl peptidase IV inhibition improves cardiorenal function in overpacing-induced heart failure. Eur J Heart Fail. 2012;14(1):14-21.

137. Chaykovska L, von Websky K, Rahnenführer J, et al. Effects of DPP-4 inhibitors on the heart in a rat model of uremic cardiomyopathy. PLoS One. 2011;6(11):e27861.

138. Ferreira L, Teixeira-de-Lemos E, Pinto F, et al. Effects of sitagliptin treatment on dysmetabolism, inflammation, and oxidative stress in an animal model of type 2 diabetes (ZDF rat). Mediators Inflamm. 2010; 2010:Article ID 592760.

139. Mega C, Teixeira de Lemos E, Vala H, et al. Diabetic nephropathy amelioration by a low-dose sitagliptin in an animal model of type 2 diabetes (Zucker diabetic fatty rat). Exp Diabetes Res. 2011;2011: Article ID 162092.

140. Collins R, Armitage J, Parish S, Sleigh P, Peto R; Heart Protection Study Collaborative Group. MRC/BHF Heart Protection Study of cholesterollowering with simvastatin in 5963 people with diabetes: a randomized placebo-controlled trial. Lancet. 2003;361(9374):2005-2016.

141. Takemoto M, Node K, Nakagami H, et al. Statins as antioxidant therapy for preventing cardiac myocyte hypertrophy. J Clin Invest. 2001;108(10):1429-1437.

142. Davignon J. Beneficial cardiovascular pleiotropic effects of statins. Circulation. 2004;109(23 Suppl 1):III39-III43.

143. Blanco-Colio LM, Tuñón J, Martín-Ventura JL, Egido J. Antiinflammatory and immunomodulatory effects of statins. Kidney Int. 2003;63(1):12-23.

144. Sola S, Mir MQ, Lerakis S, Tandon N, Khan BV. Atorvastatin improves left ventricular systolic function and serum markers of inflammation in nonischemic heart failure. J Am Coll Cardiol. 2006;47(2):332-337.

145. Horwich TB, MacLellan WR. Atorvastatin and statins in the treatment of heart failure. Expert Opin Pharmacother. 2007;8(17):3061-3068.

146. Van Linthout S, Riad A, Dhayat N, et al. Anti-inflammatory effects of atorvastatin improve left ventricular function in experimental diabetic cardiomyopathy. Diabetologia. 2007;50(9):1977-1986.

147. Ye P, Sheng L, Zhang C, Liu Y. Atorvastatin attenuating downregulation of peroxisome proliferator-activated receptor gamma in preventing cardiac hypertrophy of rats in vitro and in vivo. $J$ Pharm Pharm Sci. 2006;9(3):365-375. 
148. Shekelle PG, Rich MW, Morton SC, et al. Efficacy of angiotensinconverting enzyme inhibitors and beta-blockers in the management of left ventricular systolic dysfunction according to race, gender, and diabetic status: a meta-analysis of major clinical trials. J Am Coll Cardiol. 2003;41:1529-1538.

149. Zaman AK, Fujii S, Goto D, et al. Salutary effects of attenuation of angiotensin II on coronary perivascular fibrosis associated with insulin resistance and obesity. J Mol Cell Cardiol. 2004;37(2):525-535.

150. Orea-Tejeda A, Colín-Ramírez E, Castillo-Martínez L, et al. Aldosterone receptor antagonists induce favorable cardiac remodeling in diastolic heart failure patients. Rev Invest Clin. 2007;59(2):103-107.

151. Scheen AJ. Prevention of type 2 diabetes mellitus through inhibition of the renin-angiotensin system. Drugs. 2004;64(22):2537-2565.

152. Di Filippo C, Lampa E, Tufariello E, et al. Effects of irbesartan on the growth and differentiation of adipocytes in obese zucker rats. Obes Res. 2005;13(11):1909-1914.

153. Dandona P, Dhindsa S, Ghanim H, Chaudhuri A. Angiotensin II and inflammation: the effect of angiotensin-converting enzyme inhibition and angiotensin II receptor blockade. J Hum Hypertens. 2007;21(1): 20-27.
154. Fliser D, Buchholz K, Haller H. Antiinflammatory effects of angiotensin II subtype 1 receptor blockade in hypertensive patients with microinflammation. Circulation 2004;110:1103-1107.

155. Proudfoot JM, Croft KD, Puddey IB, Beilin LJ. Angiotensin II type 1 receptor antagonists inhibit basal as well as low-density lipoprotein and platelet-activating factor-stimulated human monocyte chemoattractant protein-1. J Pharmacol Exp Ther 2003;305:846-853.

156. Nerry Serneri GG, Boddi M, Modesti PA, et al. Cardiac angiotensin II participates in coronary microvessel inflammation of unstable angina and strengthens the immunomediated component. Circ Res. 2004;94(12):1630-1637.

157. Gullestad L, Aukrust P, Ueland T, et al. Effect of high- versus low-dose angiotensin converting enzyme inhibition on cytokine levels in chronic heart failure. J Am Coll Cardiol. 1999;34(7):2061-2067.

158. Tsutamoto T, Wada A, Maeda K, et al. Angiotensin II type 1 receptor antagonist decreases plasma levels of tumor necrosis factor alpha interleukin- 6 and soluble adhesion molecules in patients with chronic heart failure. J Am Coll Cardiol. 2000;35(3):714-721.

International Journal of Interferon, Cytokine and Mediator Research

\section{Publish your work in this journal}

The International Journal of Interferon, Cytokine and Mediator Research is an international, peer-reviewed, open-access, online journal. The focus of the journal is to publish original research, reports, editorials, reviews and commentaries on all aspects of interferon, cytokine and mediators of inflammation from labora- tory science to therapeutic indications and clinical studies. The manuscript management system is completely online and includes a very quick and fair peer-review system, which is all easy to use. Visit http://www.dovepress.com/testimonials.php to read real quotes from published authors.

Submit your manuscript here: http://www.dovepress.com/international-journal-of-interferon-cytokine-and-mediator-research-journal 